\title{
COGNITIVE APPROACH TO MODELING REFLEXIVE CONTROL IN SOCIO-ECONOMIC SYSTEMS
}

\author{
Volodymyr N. SHEMAYEV
}

\begin{abstract}
Traditional approaches to support of decision making do not consider system dynamics of processes and the individual characteristics of the actors (subjects). Considering this, the theory of reflexive control has gained wide acceptance and application. Another approach to modeling socio-economic systems is cognitive modeling. It, however, does not account for reflexivity. Therefore, this article describes a new approach that tries to combine the strengths of the two approaches to modeling of socio-economic systems.
\end{abstract}

Keywords: Subject, Cognitive Approach, Reflexive Control, Socio-Economic Systems, Direct Task, Formal Task of Cognitive Modeling.

Nowadays, a significant factor of continuously growing importance is the use of information warfare weapons by terrorist organizations.

The following tendencies and factors of the modern socio-economic situation could be outlined:

- Permanent potential threat of armed conflicts of local and regional character;

- Simultaneously, a substantial decrease of the opportunities for involvement of armed forces;

- Increasing opportunities for realization of national interests in the military domain.

Considering the interests of the other actors/ subjects is a general feature in the evaluation and prediction of development in socio-economic systems.

The features that are important for description in the process of evaluation and prediction of development in socio-economic systems are as follows:

- Correlation and diversity of processes; 
- $\quad$ Lack of quantitative data;

- Dynamics of process parameters;

- Consideration of the interests of the other actors/ subjects.

Formally, the task of information control can be presented with the following relation:

$$
\Phi(t)=\Psi(D(F, W, M), G(t), X(t), U(t)),
$$

where:

- $\quad D(F, W, M)$ represents the structure of the situation;

- $G(t)$ - the set of objectives;

- $X(t)$ - the set of situation conditions;

- $U(t)$ - the set of controls.

Then, $U^{*}(t)$ is the rational (optimal) set of controls given by:

$$
U^{*}(t)=\underset{U(t) \in U}{\operatorname{Arg} \operatorname{opt}} \Phi(t)
$$

The traditional approaches for decision-making support (see Table 1) do not consider the system dynamics of processes and the individual characteristics of the actors (subjects) that, in addition to the objective contents, have also a pronounced subjective character. Each participating party in addition to the general information has its own idea/ perception of the situation and is willing to think and act for a different actor/ subject that provide prerequisites for reflexive control of the subject.

Table 1: Analysis of Traditional Methods and Theories.

\begin{tabular}{|l|l|l|l|}
\hline Type of Prediction & Task of Prediction & $\begin{array}{l}\text { Methods and } \\
\text { Theories }\end{array}$ & Disadvantages \\
\hline $\begin{array}{l}\text { Searching prediction } \\
\text { (direct task) }\end{array}$ & $\begin{array}{l}\text { Assessment and pre- } \\
\text { diction of situation } \\
\text { factors }\end{array}$ & $\begin{array}{l}\text { Statistics, Expert } \\
\text { systems, Fuzzy logic }\end{array}$ & $\begin{array}{l}\text { Difficult to take into } \\
\text { account conditions } \\
\text { of stochastic data, } \\
\text { direct and reverse } \\
\text { linkages between the } \\
\text { situation's factors }\end{array}$ \\
\hline $\begin{array}{l}\text { Normative prediction } \\
\text { (reverse task) }\end{array}$ & $\begin{array}{l}\text { Synthesis of decision } \\
\text { alternatives and se- } \\
\text { lection of rational } \\
\text { decision }\end{array}$ & $\begin{array}{l}\text { Game theory, Ana- } \\
\text { lytical Hierarchy } \\
\text { Process } 1\end{array}$ & $\begin{array}{l}\text { Impossible to use } \\
\text { "network-like" graph }\end{array}$ \\
\hline
\end{tabular}




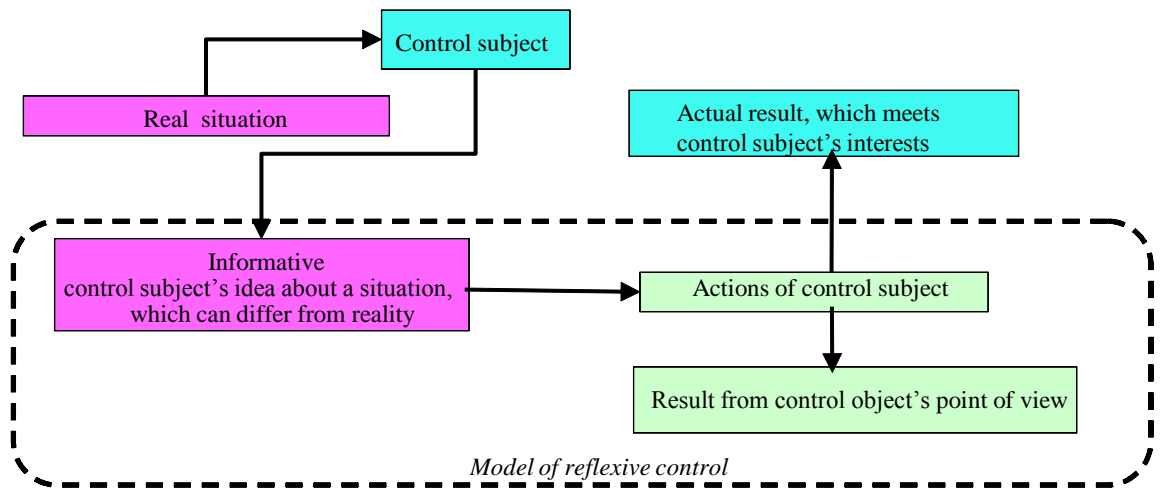

Figure 1: Model of Reflexive Control.

\section{Background on Reflexive Control}

Reflexive control (see Figure 1) is defined by Vladimir A. Lefebvre as "a process by which one enemy transmits the reasons or bases for making decisions to another.", Or, as Lefebvre puts it in the title of one of his books, reflexive control is a Soviet concept of influencing an adversary's decision-making process. ${ }^{3}$

Clifford Reid defines the concept of reflexive control as a "branch of the theory of control related to influencing the decisions of others. In a military context, it can be viewed as a means for providing a military commander with the ability to indirectly maintain control over his opponent commander's decision process."

Timothy Thomas provides the following definition: "Reflexive control is defined as a means of conveying to a partner or an opponent specially prepared information to incline him to voluntarily make the predetermined decision desired by the initiator of the action." The decision itself must be made independently. A "reflex" itself involves the specific process of imitating the enemy's reasoning or imitating the enemy's possible behavior and causes him to make a decision unfavorable to himself.

Reflexive control considers the physiological characteristics of the actors and involves intentional influence on their models of decision-making. Therefore, the problem of methodology development for reflexive control has gained importance nowadays, making serious scientific and practical contribution.

There are a number of well-known scientists, working in the area of information warfare and reflexive theory. Among them, the following scientists working in the civilian sector have to be mentioned: Vladimir A. Lefebvre, Lewis Dudley Miller, G. P. Shchedrovitsky, Vladimir E. Lepsky, S. Rastorguyev, V. A. Petrovsky, C. Grinyaev, Georgij Pocheptsov, Tatyana A. Taran, and others. 
The foremost theorists working in the military sector are: Timothy L. Thomas, V. V. Druzhinin, M. D. Ionov, D. S. Kontorov, S. Leonenko, G. Grachov, N. I. Turko, F. Chausov, S. Komov, A. Malkov, and O. Litvinenko.

The theory of reflexive control has got wide distribution and broad application based mainly on the innovative ideas of Vladimir A. Lefebvre that were initially developed to meet the needs of major military projects in the beginning of 1960s. It had been necessary at that time to create a methodology that would allow interdisciplinary research during the modeling of various conflicts and the search for invariant methods of modeling conflicts. Lefebvre's principal achievement is that he took the notion of reasoning out of the area of philosophy, highly ideologized at that time, to apply it in the field of general systems research. That was mostly due to the introduction of the term "reflexion system." Thus the "reflexive" approach appeared, and the instrumental facilities abundantly created within its framework were validated through scientific discussions and experimental and practical work. ${ }^{6}$ The distinguishing feature of these research work was orientation on mathematical model construction of the "inner life" of a subject, which includes own image and other individuals, and also ideas about images.

Soviet Union science at that time was trying to refuse and disagree with lots of Lefebvre's ideas. The reason was the hegemony of the natural-science approach to the control of complex systems. At present, the situation has completely changed. The failure of traditional approaches to design and control of intricate systems (particularly social systems that have active elements - subjects) has been clearly acknowledged.

Specific agents (actors) with own subjective inner life that are necessary to keep in harmony with the existing normative ideas and models come to the front. Nowadays, the reflexive control movement, which is underway in Russia, influences approaches to different branches of knowledge such as philosophy, sociology, psychology, pedagogy, problems of artificial intelligence and computer science in general, computer "control" influence, military affairs, intelligence, and counterintelligence. ${ }^{7}$ The reflexive approach finds both military and civilian applications.

We are not going into details of the theory of reflexive control in this article. Among other things, Lefebvre has created equations that are supposed to predict the largescale consequences of individual actions. Among the parameters in the equations are the self image of the individual and the action as perceived via this self image. The result is a number expressing the probability that the individual in question will perform a specific action. 


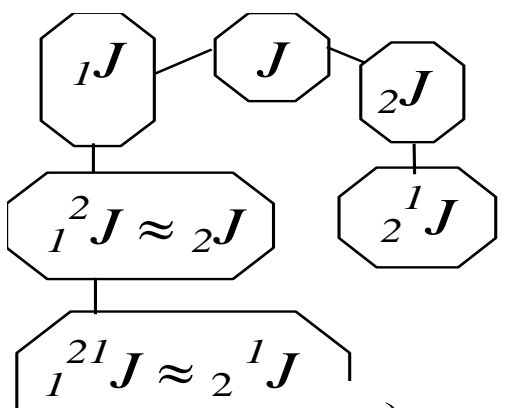

a)

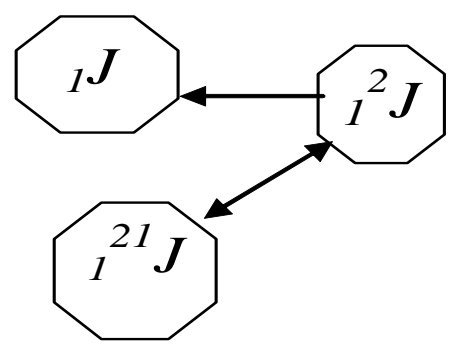

b)

Figure 2: Models of Reflexive Cooperation of Subjects at the First Level of Reflection.

A very comprehensive article by Timothy Thomas describes both the theory and practice of reflexive control, focusing on recent developments. ${ }^{8}$ According to Thomas, the concept of reflexive control is similar to the US concept of perception management. Another article by Stuart Umpleby provides a more general discussion of reflexivity in social systems and presents mainly the theories and interpretations of George Soros, but the paper also briefly reviews the other reflexive theories in cybernetics. ${ }^{9}$

Although the theory of reflexive control has been studied in the Soviet Union and Russia for almost 40 years already, it is still undergoing further refinement and development. Recent proof of this is the launch in February 2001 of a new Russian journal Reflexive Processes and Control. ${ }^{10}$ According to the editorial council, the journal is the product of some of Russia's leading national security institutes.

In general, the models proposed by Lefebvre are descriptive in nature, which means that it is difficult to get practical results using them.

For illustration purposes, Figure 2 presents models of reflexive cooperation of subjects at the first level of reflection, where part (a) of the Figure presents a hierarchy of information models and part (b) presents a graph reflective cooperation of subjects.

\section{Methodology of Cognitive Modeling}

Another approach to modeling socio-economic systems is cognitive modeling. Cognitive modeling based on fuzzy cognitive maps is considered to be one of the best ways to formalize control processes in social-politic and economic systems. Such a mathematical model allows both to analyze the situation in-system and to synthesize a control strategy.

There are a great number of reception methods, presentation and analysis of subjective presentations of subject about the processes of functioning of the weakly struc- 


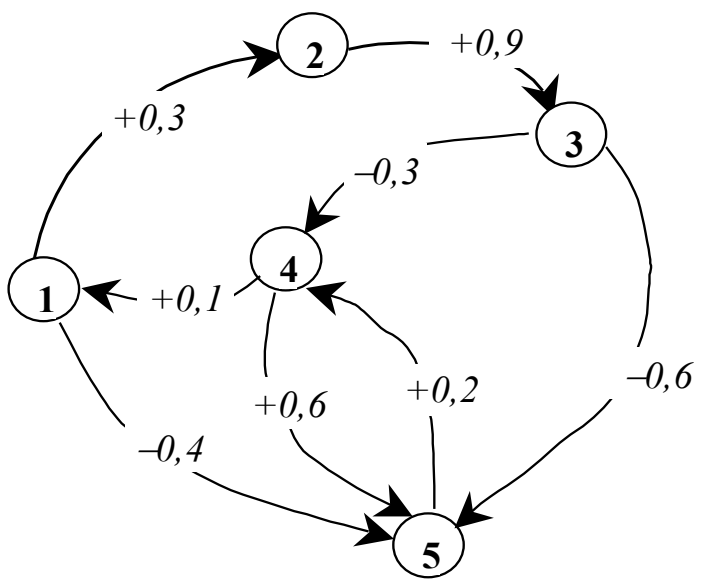

Figure 3: Causal-Loop Diagrams in System Dynamics.

tured unique situations and development methods of strategies for control of these situations.

Recently, the method of System Dynamics or System Dynamics Simulation Modeling, developed by Jay Forrester in the 1960s, has gained wide acceptance. ${ }^{11}$

Systems dynamics is a method for understanding the dynamic behavior of complex systems. It deals with internal feedback loops and time delays that affect the behavior of the entire system. The rationale of the method is based on the idea that a certain system can be represented as a complex structure, the parts (individual components) of which are closely connected and influence one another positively or negatively (see Figure 3). Inter-element coupling can be open-ended or close-ended (contour), that depends on a primary change in the element that can go through the contour of the feedback loop and influence the same element again. Structural complexity and internal action define the reaction of a system on environmental effect and its behavioral path in the future. It can differ from expected in some time and be reversed as a result of its internal changes.

Within System Dynamics Simulation Modeling, a model that reflects the internal structure of a system is created. Then the model behavior is studied by computer simulation for the future. It provides opportunity to investigate system behavior in general and that of its components as well.

The method of System Dynamics Simulation Modeling can be described by the following expression:

$$
J_{S}=<F, W, M>
$$


Table 2: Steps in Cognitive Analysis and Situation Development Control.

Structuring of knowledge about the situation.

Building a cognitive model of the situation.

Investigating the tendencies of situation development and its control:

- Prediction of situation self-development;

- Synthesis of scenario for control of situation development.

Selection and detailed elaboration of decisions about moving the situation from the current to the target one

where $F=\left\{F_{1}, \ldots, F_{k}\right\}$ is the set of situation factors, the assessment points of the factors are in the interval $[-1,1]$.

The factors can be target, operation's and system's.

The basic steps of cognitive analysis and situation development control are presented in Table 2.

The direct and reverse tasks of cognitive modeling are given below.

Direct task - cognitive modeling

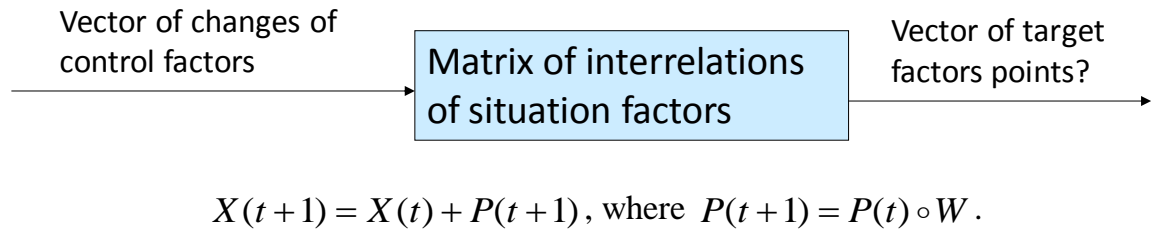

( ० ) - max-product-composition.

Reverse task - cognitive modeling

Vector of desired points of target factors

\section{Matrix of interrelations} of situation factors

$$
U \circ W=G,
$$$$
\Omega=\left\{U_{1}, U_{2}, \ldots, U_{k}\right\},
$$

Where $U_{1}, U_{2}, \ldots, U_{k}$ is the set of control factor points.
Vector of the required points of control factors ? 


\section{Reflexive Control}

$\checkmark$ Considers physiological characteristics of humans and involves intentional influence on their models of decision making.

Models are descriptive, which means that it is difficult to get practical results.

$\checkmark$ Application of these results is limited because of the specifics of mathematical models that do not consider the structure and dynamics of evolution and development.

\section{Cognitive Modeling}

$\checkmark$ A model that reflects the internal structure of a system is created. Then the model behavior is studied by a computer for the future. It gives an opportunity to investigate the system behavior in general and that of its components as well.

Character of reflection is not presented in these models, therefore it is rather difficult to define the strategy of reflexive control by cognitive maps.

A new approach bridges the gap between the two ways of finding a solution when conflict situations occur. It is proposed to make a system of representations of each conflict party in the form of fuzzy cognitive maps. The task of reflexive control is then to create such representation about a situation for one of the parts that will make the other part to benefit.

Figure 4: A cognitive Approach to Modeling Reflexive Conrol.

However, the character of reflection is not considered in these models; therefore, it is rather difficult to define the strategy of reflexive control by cognitive maps. On the other hand, there is a scientific school headed by V. Lefebvre that studies reflexive processes within mathematical psychology. Nevertheless, application of these results is limited because of the specifics of mathematical models that do not consider the structure and dynamics of developments.

To overcome some of the difficulties in modeling, Shamayev and Taran proposed a new method that bridges the gap between the two approaches to finding a solution when conflict situations occur (see Figure 4). ${ }^{12}$ The authors propose to make a system of representations of each conflict party in the form of fuzzy cognitive maps. The task of reflexive management is to create such representation about a situation for one of the parts that will make the other part benefit.

Sample of information model of subjects' cooperation is presented in Figure 5. Direct and reverse tasks are used for cognitive analysis and reflexive control of situation development. 


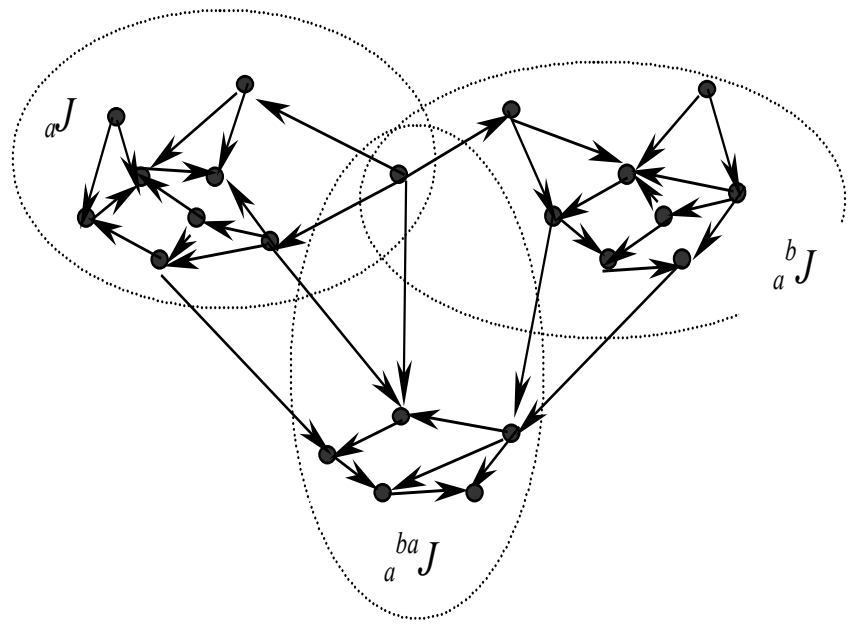

Figure 5: Information Model of Subjects' Cooperation.

\section{Notes:}

1 Thomas L. Saati, The Analytic Hierarchy Process for Decision in a Complex World (Pittsburgh, PA: RWS Publications, 1980); Thomas L. Saaty, Fundamentals of Decision Making and Priority Theory with the Analytic Hierarchy Process, Volume 6 of Analytic Hierarchy Process Series (Pittsburgh, PA: RWS Publications, June 2000).

2 Vladimir A. Lefebvre, Elements of Reflexive Games Logic (Moscow, 1966).

3 Vladimir A. Lefebvre, Reflexive Control: The Soviet Concept of Influencing an Adversary's Decision Making Process (Moscow: Science Applications, 1984). 
${ }^{4}$ Clifford Reid, "Reflexive Control in Soviet Military Planning," in Soviet Strategic Deception, ed. Brian Daily and Patrick Parker (Lexington, Mass.: Lexington Books, 1987), 293-311.

5 Timothy L. Thomas, "Russia's Reflexive Control Theory and the Military," Journal of Slavic Military Studies 17 (2004): 237-256, <www.rit.edu/ cmmc/conferences/2007/ literature/Thomas_2004.pdf> (23 November 2007).

6 "Scientific and Socio-Cultural Role of Reflexive Movement in Russia," Round Table Discussion (Russian Academy of Sciences: Institute of Psychology, 5 March 2001) Reflexive Processes and Control 1, no. 1 (2002): 6-28.

7 Thomas, "Russia's Reflexive Control Theory and the Military."

8 Thomas, "Russia's Reflexive Control Theory and the Military."

9 Stuart A. Umpleby, "Reflexivity in Social Systems: The Theories of George Soros" (a paper presented at the annual meeting of the American Society for Cybernetics, Washington, DC: The George Washington University, 27-30 October 2005),

${ }^{10}$ See <www.reflexion.ru/EJournal.html> (23 November 2007).

${ }^{11}$ Jay W. Forrester, Industrial Dynamics (Cambridge MA: MIT Press, 1961); Jay W. Forrester, "The Beginning of System Dynamics," Banquet Talk at the international meeting of the System Dynamics Society, Stuttgart, Germany, 13 July 1989, <sysdyn.clexchange.org/sdep/papers/D-4165-1.pdf>.

${ }^{12}$ Tatyana A. Taran and Volodymyr N. Shemayev, "Cognitive Regulation of Reflexive Processes" (Kiev, 2004); Tatyana A. Taran and Volodymyr N. Shemayev, "Boolean Reflexive Control Models and Their Application to Describe the Information Struggle in Socio-Economic Systems," Automation and Remote Control 65, no. 11 (November 2004): 1834-1846.

PROF. VOLODYMYR SHEMAYEV is head of the Department of Economics and Finance of the National Defence Academy of Ukraine, Kyiv. His scientific interests include Reflexive Control, Information Security, Defence Planning and Budgeting, and Ukraine's Integration to NATO.E-mail: shemayev@inbox.ru. 